\title{
SLOW STRAIN RATE TENSILE TESTS ON IRRADIATED AUSTENITIC STAINLESS STEELS IN SIMULATED LIGHT WATER REACTOR ENVIRONMENTS
}

\author{
Y. Chen ${ }^{1}$, A. S. Rao ${ }^{2}$, B. Alexandreanu ${ }^{1}$, K. Natesan ${ }^{1}$ \\ ${ }^{1}$ Nuclear Engineering Division, Argonne National Laboratory, Argonne, IL 60439, USA \\ ${ }^{2}$ US Nuclear Regulatory Commission, Washington, DC 20555, USA \\ E-mail of corresponding author: yiren_chen@anl.gov
}

\begin{abstract}
Irradiation stress corrosion cracking (IASCC) is a critical degradation mechanism for reactor internal components that contributes to the safety and economic operation of reactors. As nuclear power plants age and irradiation dose increases, IASCC becomes an increasingly important issue because of its potential impact on the integrity of reactor internal components. In this study, slow strain rate tensile tests were conducted on irradiated tensile specimens at strain rates between 3 to $7 \times 10^{-7} \mathrm{~s}^{-1}$ to evaluate cracking susceptibility of austenitic stainless steels in simulated light water reactor (LWR) environments. Significant increases in yield strength were observed for all irradiated specimens and a dose dependence of irradiation hardening was obtained at temperatures relevant to LWRs. Ductility and strain hardening capability were also found decrease rapidly with the increase of dose. After the tests, the specimens were examined using a scanning electron microscopy to characterize fracture morphology. The area fractions of non-ductility fracture were used to evaluate the IASCC susceptibility along with the tensile properties. IASCC susceptibility was also compared for several stainless steels irradiated in the Halden and BOR-60 reactors. A possible neutron spectrum effect was discussed.
\end{abstract}

\section{INTRODUCTION}

Non-sensitized austenitic stainless steels (SSs) used in the core internals of light water reactors (LWRs) have experienced stress corrosion cracking (SCC) after extended neutron exposure. Pre-mature failures resulting from SCC have been observed in SS components such as fuel cladding, absorber tubes, core shrouds, and top guides in boiling water reactors (BWRs), and fuel cladding, control rod cladding, and baffle former bolts in pressurized water reactors (PWRs) [1-4]. The elevated susceptibility to SCC in irradiated materials, commonly termed as irradiation-assisted stress corrosion cracking (IASCC), is a complex phenomenon that involves simultaneous actions of neutron irradiation, applied stress, and corrosive environment. As nuclear power plants age and neutron fluence increases, IASCC has become a key issue in recent years for the license renewal and aging management of light water reactors (LWRs) world wide.

Neutron irradiation plays a key role in IASCC. Irradiation-induced microstructural (e.g., radiation defects) and microchemical (e.g., radiation-induced segregation) changes in the material, along with changes in water chemistry (e.g., radiolysis), give rise to IASCC $[5,6]$. A number of micro-mechanisms associated with irradiation damage have been considered for IASCC $[7,8]$. While significant progress has been made to understand cracking response to corrosion potential, exact underline mechanism in LWR environments remains unclear $[9,10]$. In BWRs, a characteristic rise in IASCC susceptibility has been observed for a neutron dose of $0.45 \sim 0.75$ displacements per atom (dpa) [6,11]. In PWRs, environmentally assisted cracking has been seen at a higher dose about 1.5 3 dpa [6]. The hydrogenated primary coolant in PWRs is believed to be responsible for the improved IASCC resistance compared to the BWR environment. With a low corrosion potential, irradiation damage may play an even more important role in elevating cracking susceptibility in PWR environments.

Irradiation hardening and embrittlement are key irradiation effects that have significant impacts on IASCC behavior of austenitic SSs. While the hardening and embrittlement of austenitic SSs have been studied extensively over the dose range relevant to LWR applications, actual data obtained at LWR operational temperatures are rare in literature. Most research on irradiation effects was focused on either embrittlement issues at low temperatures or creep properties at high temperatures. Irradiation effects at intermediate temperatures relevant to LWR applications were not explored extensively. Meanwhile, it is known that both irradiation and deformation behaviors of austenitic SSs are sensitive to neutron dose at intermediate temperatures around $300^{\circ} \mathrm{C}[12,13]$. Thus, to study LWR internals, it is necessary to understand the dose dependences of irradiation hardening and embrittlement of austenitic SSs at LWR-relevant temperatures. 


\section{EXPERIMENTAL}

\section{Materials and Specimens}

Several commercial and laboratory heats of austenitic SSs were included in this study. The materials were 304 and 304L SSs either in solution-annealed (SA) or cold-worked (CW) condition. Two grain boundary engineered (GBE) $^{*}$ heats were also included. Table 1 provides the chemical compositions and thermo-mechanical conditions of these materials.

Table 1. Materials included in this study.

\begin{tabular}{|c|c|c|c|c|c|c|c|c|c|c|}
\hline \multirow{2}{*}{$\begin{array}{l}\text { Mat. } \\
\text { Type }\end{array}$} & \multirow[t]{2}{*}{ Material $^{*}$} & \multicolumn{9}{|c|}{ Composition (wt.\%) } \\
\hline & & $\mathrm{Ni}$ & $\mathrm{Si}$ & $\mathrm{P}$ & $\mathrm{S}$ & $\mathrm{Mn}$ & $\mathrm{C}$ & $\mathrm{N}$ & $\mathrm{Cr}$ & Other Elements \\
\hline \multirow{5}{*}{304} & 304 SA (Ht. 333) & 8.45 & 0.68 & 0.027 & 0.019 & 1.38 & 0.04 & 0.068 & 18.54 & Mo 0.37 \\
\hline & 304 SA (Ht. C9) & 8.75 & 0.39 & 0.013 & 0.013 & 1.72 & 0.062 & 0.065 & 18.48 & $\mathrm{~B}<0.001$, O 0.01 \\
\hline & 304 SA, (Ht. C12) & 8.12 & 0.50 & 0.038 & 0.002 & 1.00 & 0.060 & 0.060 & 18.11 & В 0.001, O 0.01 \\
\hline & $304 \mathrm{CW}$ & 8.23 & 0.47 & 0.018 & 0.002 & 1.00 & 0.060 & 0.070 & 18.43 & $\mathrm{~B}<0.001$ \\
\hline & 304 GBE & 8.19 & 0.41 & 0.029 & 0.006 & 1.73 & 0.054 & 0.052 & 18.28 & Mo 0.23 , Co 0.10 , Cu 0.31 \\
\hline \multirow{4}{*}{ 304L } & 304L SA / CW & 8.91 & 0.46 & 0.019 & 0.004 & 1.81 & 0.016 & 0.083 & 18.55 & $\mathrm{~B}<0.001$ \\
\hline & 304L GBE & 8.33 & 0.45 & 0.028 & 0.007 & 1.74 & 0.020 & 0.090 & 18.35 & Mo $0.37, \mathrm{Cu} 0.35$ \\
\hline & HP 304L SA, high O & 9.03 & 0.03 & $<0.005$ & 0.005 & 1.11 & 0.005 & 0.003 & 19.21 & O 0.047, Mo <0.005 \\
\hline & HP 304L SA, low O & 9.54 & 0.01 & 0.001 & 0.002 & 1.12 & 0.006 & $<0.001$ & 19.71 & O 0.008, Mo 0.02 \\
\hline
\end{tabular}

* SA = solution annealed, CW = cold worked, GBE = Grain Boundary Engineered, HP = high purity.

Two types of specimens were irradiated in two reactors, Halden and BOR-60. As shown in Fig. 1, both types of specimens are flat tensile specimens with axial loading pin holes located on their shrouds. The total lengths of the Halden and BOR-60 specimens are 57 and $25 \mathrm{~mm}$, respectively. The gauge dimensions are $19.1 \times 3.15 \times 0.76$ $\mathrm{mm}$ for the Halden specimens and 7.62 x 1.52 x $0.76 \mathrm{~mm}$ for the BOR-60 specimens.

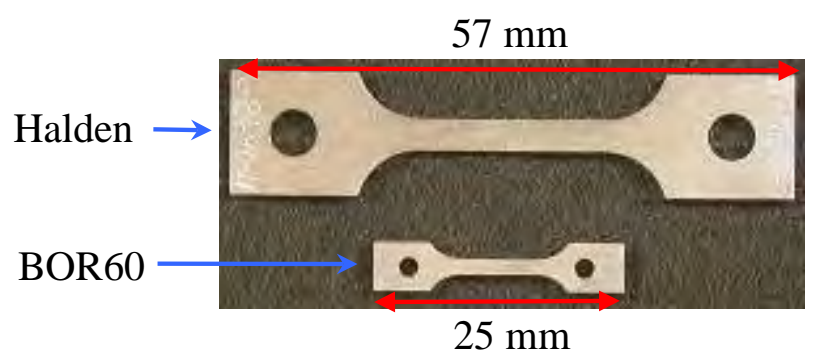

Fig.1: SSRT specimens used in this study.

\section{Irradiations}

The Halden reactor is a boiling heavy water reactor in Norway, and irradiation experiments were performed in sealed helium capsules. In these irradiations, neutron fluence was measured by activation wires. Irradiation temperature was monitored by two sets of melting alloy temperature monitors, and were between 290 and $305{ }^{\circ} \mathrm{C}$ throughout the irradiation experiments. The BOR-60 reactor is a sodium-cooled fast breeder reactor in Russia. Neutron dosimeters were loaded in the irradiation rig along with the specimens, and the final dosimetry was conducted after irradiation. During these irradiations, the specimens were in contact with sodium coolant. Irradiation temperature was controlled by monitoring the inlet and outlet sodium temperatures, which were kept at 315 and $325^{\circ} \mathrm{C}$, respectively. Magnesium-zinc eutectic thermal monitors were also placed among the specimen bundles to verify the irradiation temperature.

\section{Test Facility and Slow Strain Rate Tensile Tests}

Slow strain rate tensile tests were carried out in a hot cell facility in the Irradiated Materials Laboratory at Argonne National Laboratory (ANL). Test environment was either high-DO BWR water or hydrogenated PWR

\footnotetext{
* Grain boundary engineering is a thermo-mechanical treatment involving several strain-anneal or recrystallizationanneal iterations [14] to increase the population of coincident site lattice boundaries.
} 
primary water, and was provided by a recirculation loop next to the hot cell. The recirculation system includes a storage tank, a high-pressure pump, a back pressure regulator, and a test autoclave. The system is also equipped with online conductivity and $\mathrm{pH}$ sensors and an electrochemical potential (ECP) cell to monitor the test condition.

For the high-DO BWR water tests, high-purity water containing $\approx 8 \mathrm{ppm}$ DO was used. During these tests, autoclave temperature was at $289^{\circ} \mathrm{C}$ and pressure was maintained at $\approx 1350 \mathrm{psig}$. The flow rate of the system was $15-30 \mathrm{ml} / \mathrm{min}$, and water samples were taken periodically to monitor the resistivity, $\mathrm{pH}$, and DO level in the effluent. The conductivity and $\mathrm{pH}$ of water at room temperature were $0.06-0.10 \mu \mathrm{S} / \mathrm{cm}$ and $6.4-7.2$, respectively. The ECPs of a Pt electrode and a SS sample located downstream from the autoclave were monitored continuously during the test. The strain rate during the SSRT tests was held at $\approx 3.3 \times 10^{-7} \mathrm{~s}^{-1}$. The simulated PWR water tests were conducted at $315^{\circ} \mathrm{C}$ and 1800 psig under a constant strain of $\approx 7.4 \times 10^{-7} \mathrm{~s}^{-1}$. The PWR water contained approximately $2 \mathrm{ppm} \mathrm{Li}, 1000 \mathrm{ppm} \mathrm{B,} 2 \mathrm{ppm}$ dissolved hydrogen, and $<10 \mathrm{ppb}$ dissolved oxygen. The conductivity of the water was about $20 \mu \mathrm{S} / \mathrm{cm}$, and its $\mathrm{pH}$ was 6.6 at room temperature. The flow rate of the system was maintained at $15-30 \mathrm{ml} / \mathrm{min}$ during the tests. Prior to each test, the specimen was exposed to the subjected environment for 24 to 30 hours to stabilize test conditions.

After the SSRT tests, fracture surfaces of the tested specimens were examined with a shielded SEM to evaluate IASCC susceptibility. A fracture tip was first cut from a tested SSRT specimen with a shear device installed inside the hot cell. Then, the fracture tip was cleaned with an ultrasonic cleaner to remove loose contamination. A secondary electron image at 10 to $30 \mathrm{kV}$ acceleration voltage with a 15 to $25 \mathrm{~mm}$ work distance was used for the observations.

\section{RESULTS AND DISCUSSION}

\section{SSRT tests in simulated BWR environment}

All Halden specimens and some of the 5-dpa BOR-60 specimens were tested in high-DO BWR water. The stress-strain curves of 2-dpa Halden specimens are shown in Fig. 2. A significant amount of irradiation hardening was observed and irradiation embrittlement was evident for all specimens. Total elongation is less for low-carbon 304 SSs. No strain hardening was observed for both 304 and 304L SSs at this dose level. A significant load drop was observed after yield for both HP 304L SSs tested in this study. It is unknown at present if this reduction in strength was related to a cracking event during the test.

Because GBE treatment involves one or several iterations of strain-anneal or recrystallization-anneal iterations [14], mechanical properties of the processed specimens can be altered in addition to the modified grain boundary structure. The influence of GBE treatment on strength can be seen in Fig. 2. While the yield strength of GBE SSs is slightly higher than the nonGBE alloys, the effect on the total elongation is inconsistent for 304 and 304L SSs.
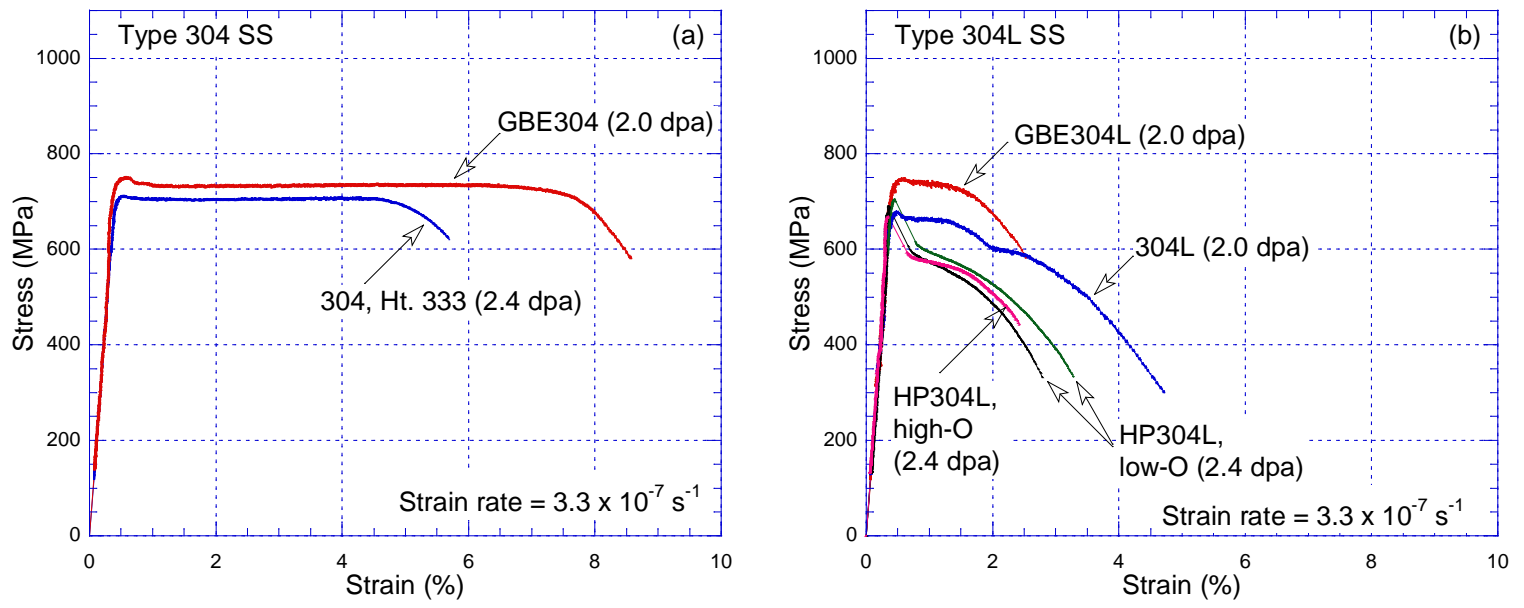

Fig. 2: Stress-strain curves of 2-dpa Halden specimens tested in $289^{\circ} \mathrm{C}$ high-DO BWR water: (a) Type 304 SSs, and (b) Type 304L SSs.

Fig. 3 shows the SSRT tests on 5-dpa BOR-60 specimens in the high-DO water environment. It is noted that, because of the different gauge dimensions of Halden and BOR-60 specimens, their total elongations are not 
directly comparable. Nonetheless, the strain-stress curves obtained in the high-DO environment are similar between Halden and BOR60 specimens. The total elongation differs considerably between the two Type 304 SSs whose sulfur contains are different. Similar to the Halden specimens, the two HP304L SSs also showed significant load drops beyond yield, indicating a cruel instability in plastic deformation.
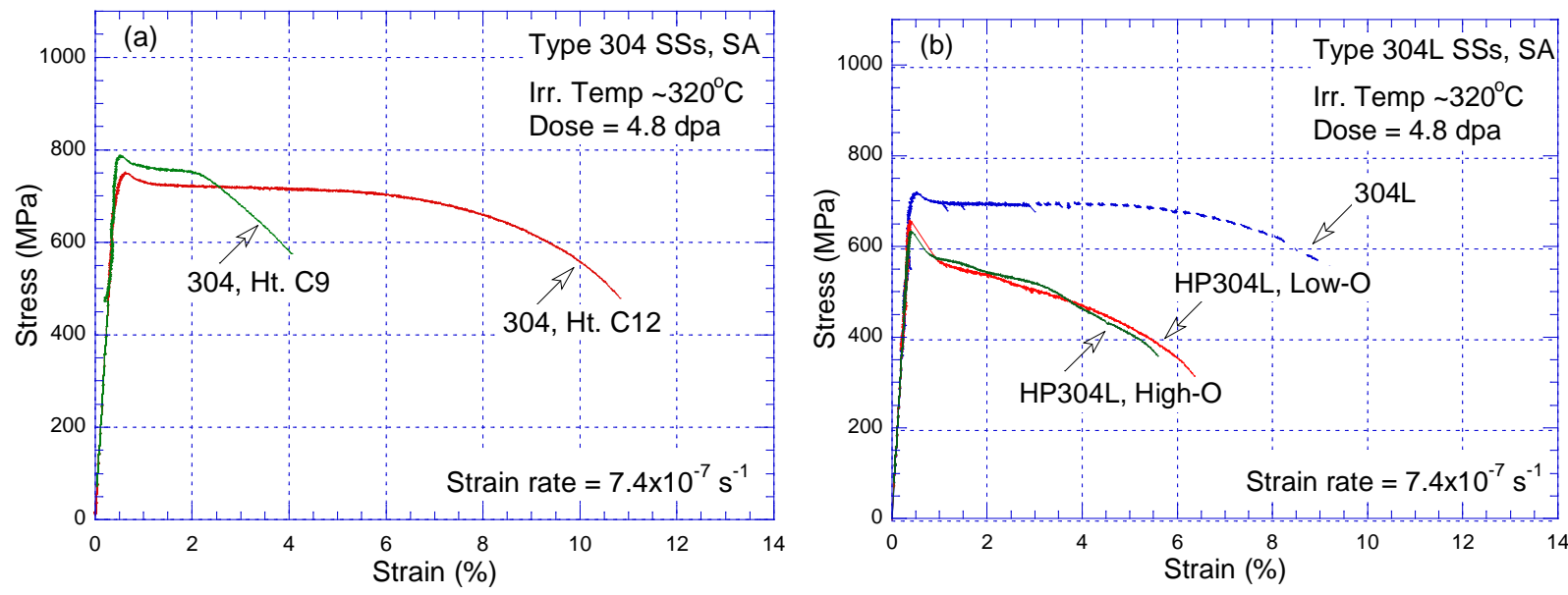

Fig. 3: Stress-strain curves of 5-dpa BOR-60 specimens tested in $289^{\circ} \mathrm{C}$ high-DO BWR water: (a) Type 304 SSs, (b) Type 304L SSs.

Fractographic examination revealed both ductile and brittle fracture features for the specimens tested in high-DO environments. Fig. 4 is the fracture surface of the 2-dpa GBE 304L SS. While ductile dimples are a major fracture mode in this sample, intergranular cracking and mixed mode fracture covers a significant area. This type of fracture surface is typical for the Halden specimens irradiated to above 1.4 dpa and tested in high-DO water. Intergranular cracking was observed for all Halden tests plotted in Fig. 2. The fractions of brittle areas varied from one alloy to another and were between 3 to $30 \%$ on the fracture surfaces. For the specimens below 0.45 dpa, fracture surfaces were fully ductile, and no brittle cracking was observed. The GBE treatment employed in this study increases the population of coincident site lattice boundaries (CSL) from $\sim 50 \%$ to $\sim 60 \%$. However, this moderate increase in CSL population seems not to have any significant impact on cracking behavior in high-DO environment, and brittle fracture appears similar for the GBE or nonGBE SSs. Thus, it appears that a $60 \%$ CSL boundaries is insufficient to mitigate cracking susceptibility of SSs in a high-DO environment.

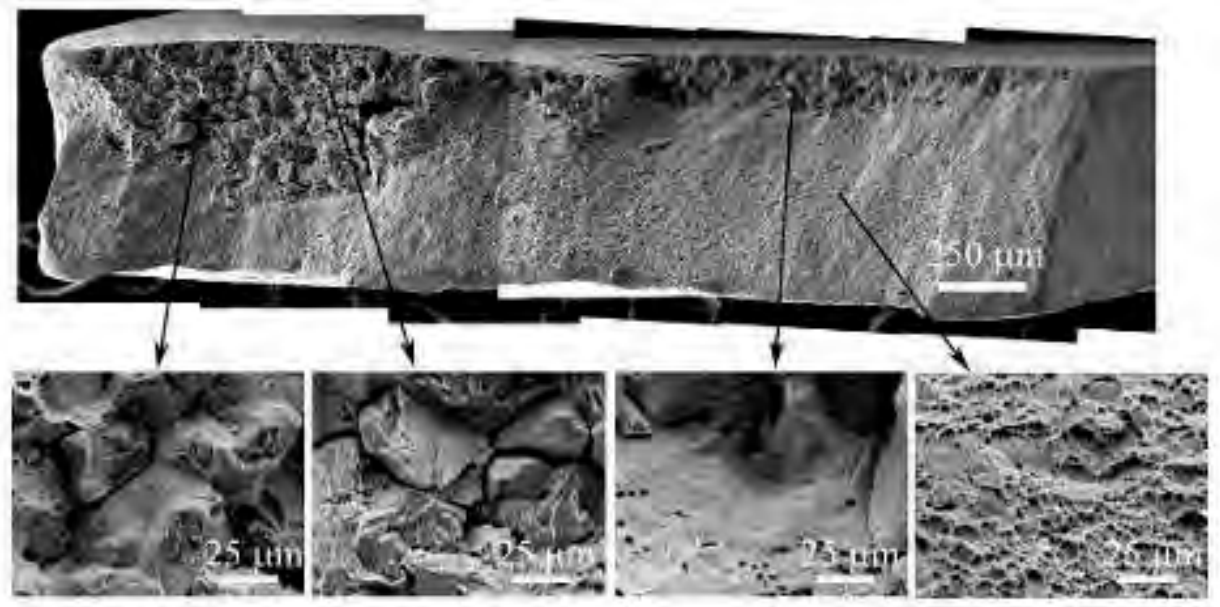

Fig. 4: Fracture surface of a 2-dpa Halden specimen (GBE 304L SS) tested in high-DO water at $289^{\circ} \mathrm{C}$. 


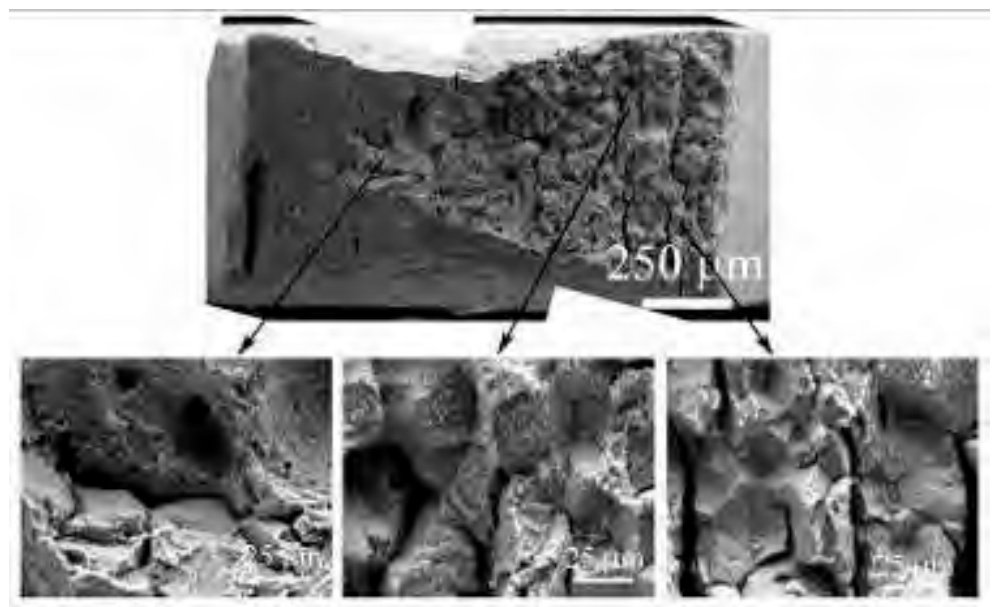

Fig. 5: Fracture surface of 5-dpa BOR-60 specimen (304 SS, Ht. C9) tested in high-DO water at $289^{\circ} \mathrm{C}$.

Fractographic examination carried out on the 5-dpa BOR-60 specimens reveals a slightly different cracking behavior. Even with a high neutron irradiation dose ( $5 \mathrm{dpa}$ ) compared to the Halden specimens ( $<3 \mathrm{dpa})$, brittle fracture was only observed in two specimens. Fig. 5 shows one of the 5-dpa BOR-60 specimens with brittle areas. The rest of the BOR-60 specimens tested in high-DO environment showed fully ductile fracture. The lack of intergranular cracking for many BOR-60 specimens is unexpected for a high-DO environment. It seems that the BOR-60 irradiation is somewhat less effective in stimulating intergranular cracking for the alloys tested in this study. The differences in the damage rate and irradiation temperature may be responsible for the observed difference in IASCC susceptibility in the two irradiations.

\section{SSRT tests in simulated PWR environment}

SSRT tests in PWR water were performed on several 10 - and 48 -dpa BOR-60 specimens at $315^{\circ} \mathrm{C}$. A typical PWR water test is shown in Fig. 6. Very little work hardening remains for this CW 304 SS specimen at 48 dpa, and the total elongation is just 3.6\%. Fractographic examination indicates that ductile dimples are the dominant features, and small transgranular areas can also be seen on the surface and at the interior of the sample (as shown in Fig. 7). No intergranular cracking was observed in this sample, and visible brittle areas were less than $2 \%$ of the whole fracture surface.

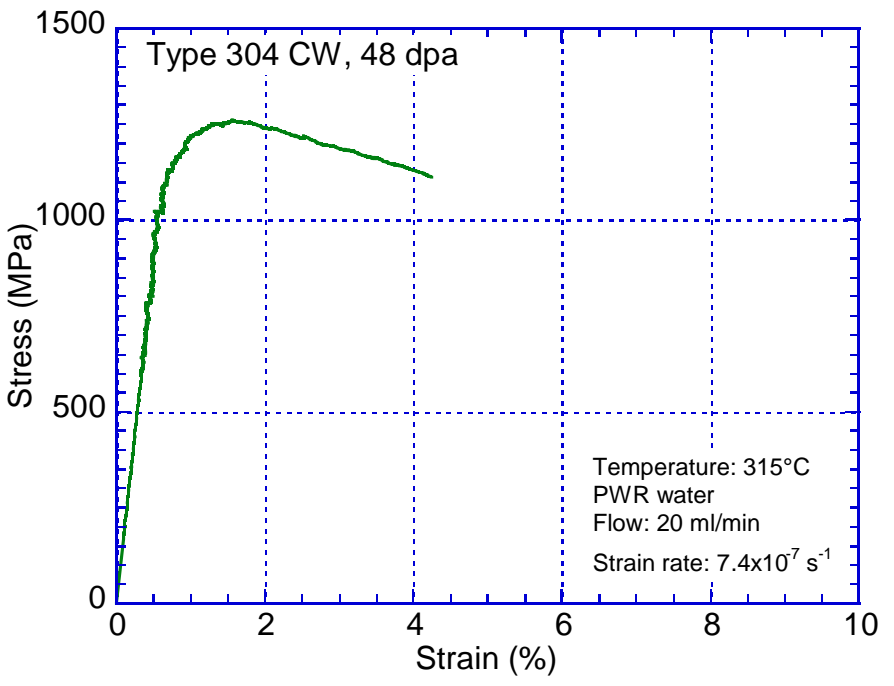

Fig. 6. SSRT stress-strain curve of a CW Type 304 SS irradiated to 48 dpa. 


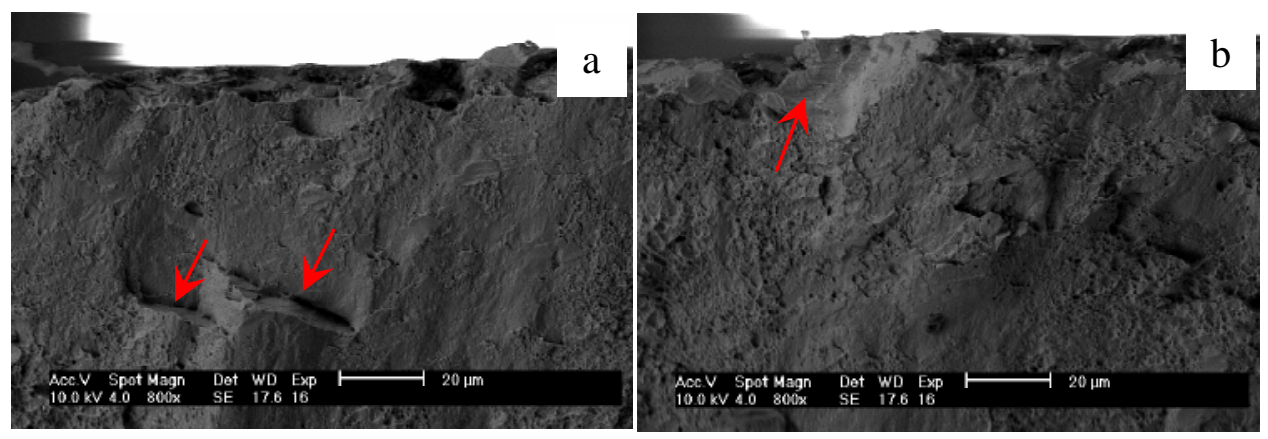

Fig. 7. Transgranular cracking in the 48-dpa CW 304 SS at sample interior (a) and on surface (b).

A comparison between SA and CW alloys were performed in the PWR water tests. Fig. 8 shows the stressstrain curves for three Type 304L SS specimens: two 10-dpa samples of SA and CW specimens and one 48-dpa CW specimen. The SA and CW samples exhibit very different stress-strain behavior. Regardless of their dose levels, the CW samples show much higher yield stresses and less elongation. The SSRT behaviors of the two CW samples are similar, with a slightly higher yield stress and less elongation for the 48-dpa sample. Ductile dimples are the main morphology of all three fracture surfaces, but detailed observations reveal several brittle areas in the CW samples as shown in Fig. 9. The 10-dpa SA sample shows a fully ductile failure, and its entire fracture surface is covered with large dimples (Fig. 9a). For the 10-dpa CW sample, although most of fracture surface exhibits a ductile dimple morphology, small transgranular cracking areas are evident, as shown in Fig. 9b. In the 48-dpa CW sample, areas of cleavage and mixed mode cracking are observed among ductile dimples that cover the majority of the fracture surface (Figs. 9c-d).

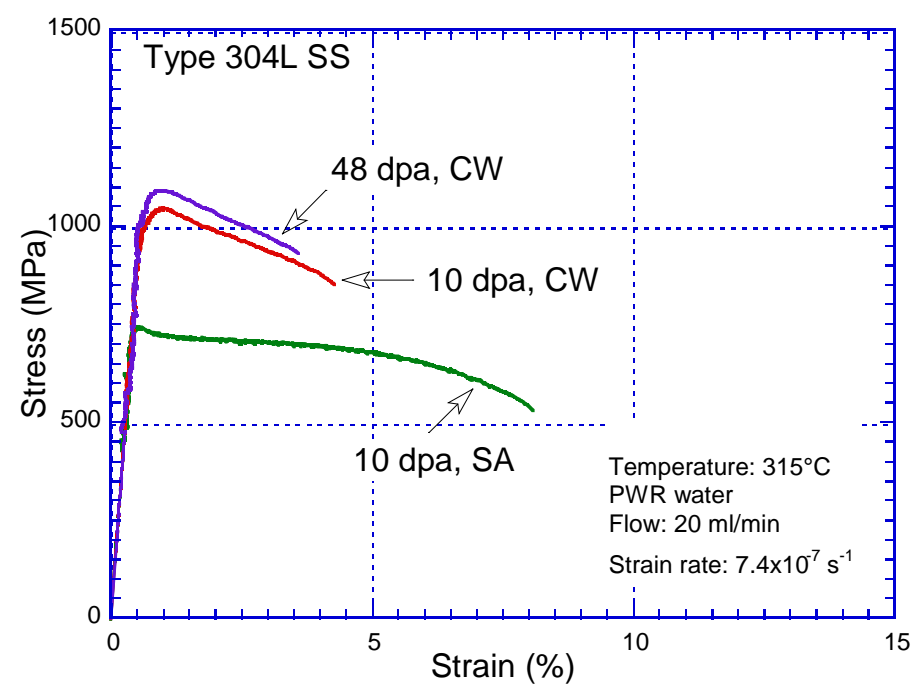

Fig. 8. SSRT stress-strain curves of SA and CW Type 304L SSs irradiated to 10 and 48 dpa. 

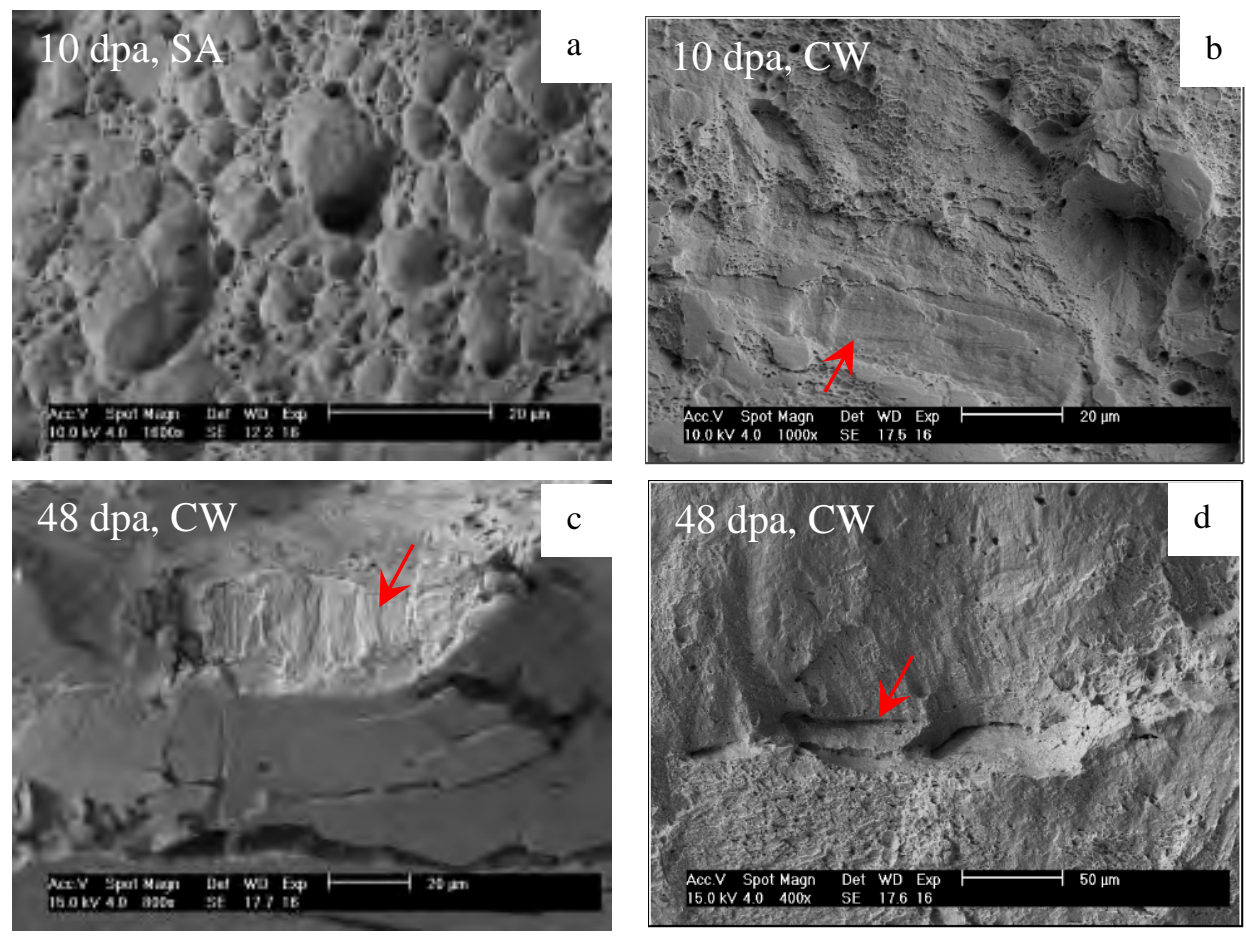

Fig. 9. Fracture morphology of 304L SSs: (a) large dimples in 10-dpa SA sample, (b) transgranular areas in 10-dpa CW sample, and (c, d) cleavage and mixed mode fracture in 48-dpa CW sample.

It appears that ductile dimple fracture was the dominant morphology for all SSRT tests in the PWR water environment. Although specimens were irradiated to much higher doses, intergranular cracking was absent among these PWR water tests. Cleavage cracking however was found in some samples at the surface, and transgranular or mixed mode cracking was seen primarily in high-dose samples. The overall fraction of brittle fracture was low (a few percent), even at $48 \mathrm{dpa}$. Despite the difference in total elongations, post-irradiation cracking susceptibility evaluated from the fracture surfaces appeared similar between SA and CW samples tested in simulated PWR water.

\section{Dose dependence of irradiation hardening}

Irradiation hardening and embrittlement have a significant impact on SSRT behavior. To assess cracking susceptibility of austenitic SSs, dose dependences of irradiation hardening and embrittlement are needed for temperatures and doses relevant to LWRs. To reveal the effects of irradiation dose, all SSRT results obtained from all Halden and BOR-60 specimens in several similar studies performed by Argonne are summarized and plotted in Fig. 10. It can be seen that all data fall into two scatter bands that represent two thermomechanical conditions, SA and CW. In general, the irradiated yield stress is higher for CW than for SA materials. The yield stress increases rapidly in the low dose region up to 5 dpa and eventually saturates at 5-10 dpa. Between 10 and 48 dpa, the yield stress is nearly unchanged. Since a wide range of austenitic SSs is included in these results, heat-to-heat variation is probably responsible for the apparent large scatter in the results.

Fig. 11 shows the total elongations as a function of dose. Since the gauge dimensions of Halden and BOR60 specimens are different, the dose dependence shown in Fig. 11 may not be quantitatively accurate. Nonetheless, a decreasing trend of ductility is indicated with increasing dose. It appears that the total elongation decreases continuously beyond $10 \mathrm{dpa}$, where irradiation hardening has already saturated. 


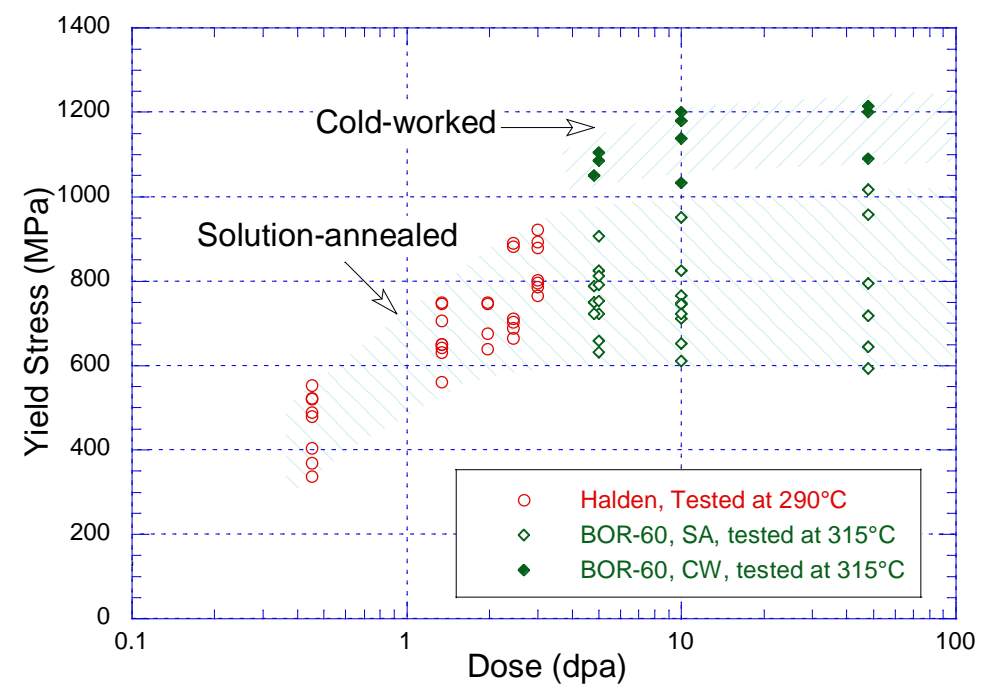

Fig. 10. SSRT yield strength as a function of irradiation dose for all tests on the BOR-60 and Halden specimens.

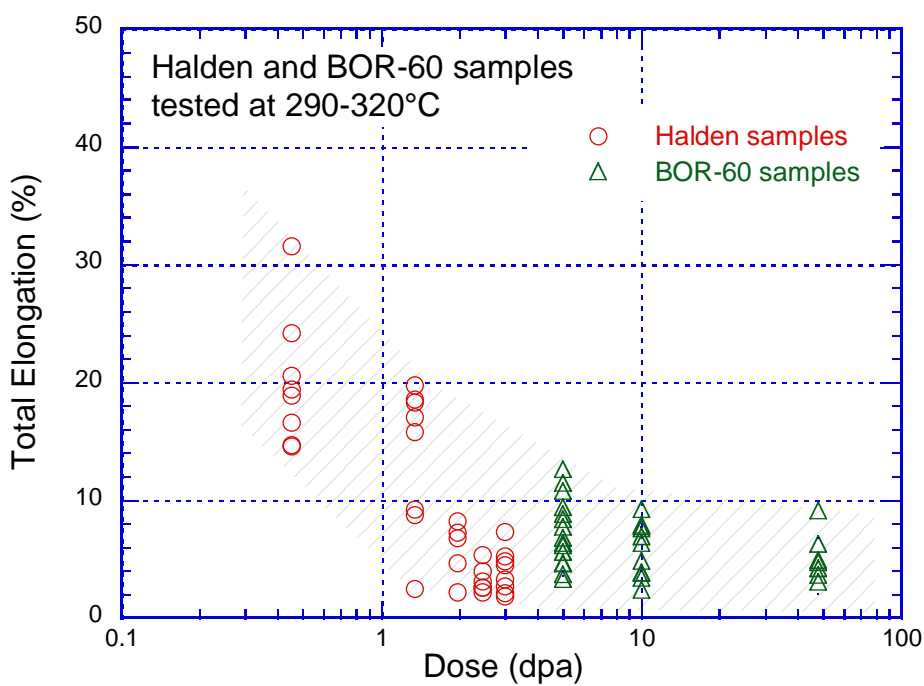

Fig. 11. Total elongation as a function of irradiation dose for BOR-60 and Halden specimens.

\section{CONCLUSION}

Slow strain rate tensile tests were performed on neutron irradiated Types 304 and 304L SSs in high-DO BWR and PWR environments. Significant irradiation hardening was observed in all SSRT tests. The saturation of irradiation hardening appears to be below $10 \mathrm{dpa}$ at LWR temperatures. Work hardening capability decreased considerably in the irradiation specimens, and above 2-5 dpa, very little work hardening was evident. The SSRT behavior of SA specimens was also compared with that of the CW specimens under similar irradiation and test conditions. The effect of CW on SSRT behavior remained unchanged up to $48 \mathrm{dpa}$. While the SSRT tests in highDO BWR water produced similar results in both Halden and BOR-60 tests, the BOR-60 irradiation seemed somewhat less effective in stimulating IASCC among the tested materials. For the PWR tests, ductile dimples were the main fracture morphology and intergranular cracking was not often seen. Cleavage cracking was found in some high-dose samples tested in PWR water, but the overall fraction of brittle fracture was very low.

\section{ACKNOWLEDGEMENTS}

The authors would like to thank Dr. O. K. Chopra for his invaluable contribution to this program. Ms. Torill Karlson, Mr. Anders Jenssen, Dr. Raj Pathania and Dr. Peter Scott are acknowledged for helping arrange neutron 
irradiations and transfer irradiated specimens. We are also grateful to Drs. W. H. Cullen, Jr., R. Tregoning, and S. Crane for many helpful discussions and suggestions. This work is sponsored by the Office of Nuclear Regulatory Research, U.S. Nuclear Regulatory Commission, under Job Code N6519; Program Manager: A. S. Rao.

\section{REFERENCES}

[1] Craig F. Cheng, "Intergranular Stress-Assisted Corrosion Cracking of Austenitic Alloys in Water-Cooled Nuclear Reactors,” J. Nucl. Mater., 56 (1975) 11-33.

[2] F. Garzarolli, H. Rubel, and E. Steinberg, "Behavior of Water Reactor Core Materials with Respect to Corrosion Attack,” Proc. Intl. Symp. on Environmental Degradation of Materials in Nuclear Power Systems -- Water Reactors, NACE, Houston, TX, pp. 1-24, 1984.

[3] F. Garzarolli, D. Alter, and P. Dewes, "Deformability of Austenitic Stainless Steels and Nickel-Base Alloys in the Core of a Boiling and a Pressurized Water Reactor," Proc. Intl. Symp. on Environmental Degradation of Materials in Nuclear Power Systems - Water Reactors, American Nuclear Society, La Grange Park, IL, pp. 131-138, 1986.

[4] R. L. Jones, J. D. Gilman, and J. L. Nelson, "Controlling Stress Corrosion Cracking in Boiling Water Reactors,” J. Nucl. Mater., 143 (1993) 111.

[5] Bruemmer, S. M. and G. S. Was, "Microstructural and Microchemical Mechanisms Controlling Intergranular Stress Corrosion Cracking in Light-Water-Reactor Systems,” J. Nucl. Mater., 216, 348-363, 1994.

[6] Scott, P., “A Review of Irradiation Assisted Stress Corrosion Cracking,” J. Nucl. Mater., 211, 101-122, 1994.

[7] G. S. Was, and S. M. Bruemmer, "Effect of Irradiation on Intergranular Stress Corrosion Cracking,” J. Nucl. Mater., 216 (1994) 326.

[8] S. M. Bruemmer, and G. S. Was, "Microstructural and Microchemical Mechanisms Controlling Intergranular stress corrosion cracking in light-water-reactor systems,” J. Nucl. Mater., 216 (1994) 348.

[9] P. L. Andresen, F. P. Ford, S. M. Murphy, and J. M. Perks, "State of Knowledge of Radiation Effects on Environmental Cracking in Light Water Reactor Core Materials,” Proc. 4th Intl. Symp. on Environmental Degradation of Materials in Nuclear Power Systems--Water Reactors, NACE, Houston, TX, pp. 1.831.121, 1990.

[10] G. S. Was, and P. L. Andresen, "Stress Corrosion Cracking Behavior of Alloys in Aggressive Nuclear Reactor Core Environments,” Corrosion, 63 (1), (2007), 19.

[11] Y. Chen, O. K. Chopra, W. K. Soppet, N. L. Dietz Rago, and W. J. Shack, "IASCC Susceptibility of Austenitic Stainless Steels and Alloy 690 in High Dissolved Oxygen Water Environment," Proc. 13th Intl. Symp. on Environmental Degradation of Materials in Nuclear Power Systems - Water Reactors, 2007.

[12] S. J. Zinkle, P. J. Maziasz, and R. E. Stoller, "Dose Dependence of the Microstructural Evolution in Neutron-Irradiated Austenitic Stainless Steel,” J. Nucl. Mater., 206 (1993) 266.

[13] P. J. Maziasz, "Overview of Microstructural Evolution in Neutron-Irradiated Austenitic Stainless Steels," J. Nucl. Mater., 205 (1993) 118.

[14] Randle, V., “Twinning-Related Grain Boundary Engineering,” Acta Materialia 52, 4067-4081, 2004. 